\title{
Prevalence of HIV-related thrombocytopenia among clients at Mbarara Regional Referral Hospital, Mbarara, southwestern Uganda
}

This article was published in the following Dove Press journal:

Journal of Blood Medicine

10 April 2015

Number of times this article has been viewed

Ivan M Taremwa'

Winnie R Muyindike ${ }^{2}$

Enoch Muwanguzi'

Yap Boum II 1,3

\section{Bernard Natukunda'}

'Department of Medical Laboratory Sciences, Faculty of Medicine, Mbarara University of Science and Technology, ${ }^{2}$ Immune Suppression Syndrome Clinic, Mbarara Regional Referral Hospital, ${ }^{3}$ Epicentre Mbarara Research Centre, Mbarara, Uganda

\section{Video abstract}

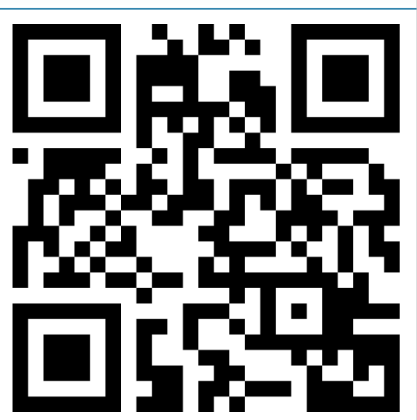

Point your SmartPhone at the code above. If you have a QR code reader the video abstract will appear. Or use: http://dvpr.es/IB2Reos
Correspondence: Ivan M Taremwa Department of Medical Laboratory Sciences, Faculty of Medicine, Mbarara University of Science and Technology, PO Box 1410, Mbarara, Uganda Tel +256774346368

Email imugisha@ymail.com
Aims/objectives: We aimed to determine the prevalence and correlates of thrombocytopenia among people living with human immunodeficiency virus (HIV)/acquired immune deficiency syndrome (AIDS) and to assess occurrence of antiplatelet antibodies, among thrombocytopenic HIV clients at Mbarara Regional Referral Hospital, southwestern Uganda.

Materials and methods: This was a retrospective review of hematologic results at enrollment to HIV care from 2005 to 2013. The prevalence and correlates of thrombocytopenia were estimated based on the Immune Suppressed Syndrome (ISS) Clinic electronic database. A cross-sectional study determined the occurrence of antiplatelet antibodies, using the monoclonal antibody-specific immobilization of platelet antigens (MAIPA) technique.

Results: We reviewed 15,030 client records. The median age was 35.0 (range 18-78; interquartile range [IQR] 28-42) years, and there were $63.2 \%(n=9,500)$ females. The overall prevalence of thrombocytopenia was $17.4 \%$ (95\% confidence interval [CI]: 16.8\%-18.0\%). The prevalence of thrombocytopenia was $17.8 \%$ (95\% CI: $17.1 \%-18.4 \%)$ among antiretroviral therapy (ART)-naïve clients $(n=2,675)$ and was 13.0\% (95\% CI: 0.3\%-21.9\%) for clients who were on ART $(n=6)$. The study found a significant association between thrombocytopenia and other cytopenias, CD4 counts, ART, and deteriorating HIV stage $(P<0.05)$. Two of the 40 participants $(5.0 \%)$ had antiplatelet antibodies.

Conclusion: This study has showed a high prevalence of HIV-related thrombocytopenia. Antiplatelet antibodies were found in 5.0\% of HIV-infected thrombocytopenic participants. Our study shows a significant association of thrombocytopenia burden in a high-HIV study population (Southwest Uganda); therefore, there is need to monitor platelet counts and initiate platelet transfusion in our blood banking practices, to avert possible risks of bleeding.

Keywords: antiplatelet antibodies, cytopenia, AIDS

\section{Introduction}

Deranged hematological parameters, including thrombocytopenia, are features of human immunodeficiency virus (HIV) infection. ${ }^{1}$ Thrombocytopenia, defined by platelet cell count of less than $150 \times 10^{9} / \mathrm{L},{ }^{2,3}$ occurs in about $4 \%-24 \%$ of HIV-infected cases. ${ }^{4,5}$ Mechanisms for thrombocytopenia, such as platelet involvement in immune responses, cytopathic effect of antiretroviral therapy (ART) regimens, and antigenic mimicry, are key in a setting of HIV. ${ }^{6,7}$ Thrombocytopenia has been linked to adverse sequelae and is regarded as an independent predictor of morbidity and mortality among the HIV-infected group, owing to increased risk of bleeding, which may occur in the mucous membranes, skin, soft tissue, and intracranial sites. ${ }^{8,9}$ The associated bleeding may cause death if it involves critical sites. ${ }^{10}$ To avert the risk of bleeding, 
platelet transfusion may be indicated; however, in Uganda, component transfusion is not readily available, ${ }^{11}$ which limits success of clinical interventions in an immunologically compromised population. Although cytopenias have been widely reported in HIV infection, there is little data regarding prevalence, correlates, and etiologic association of HIV-related thrombocytopenia in Uganda. This study sought to determine HIV-related thrombocytopenia in a high-HIV/ acquired immune deficiency syndrome (AIDS) study population (Southwest Uganda). The findings from this study will form a basis for management of complications that arise from thrombocytopenia among HIV clients in this setting.

\section{Materials and methods Study participants}

These were HIV-positive adult males and females who had been enrolled for care at the Immune Suppressed Syndrome (ISS) Clinic in Mbarara, Uganda. The hematologic results were retrieved from the ISS database. We sought informed consent of patients with thrombocytopenia as found in their previous full blood count (FBC) results, and investigated the presence of antiplatelet antibodies.

\section{Sample collection}

Blood was drawn, with minimal stasis, from the antecubital vein. For each sample, $3 \mathrm{~mL}$ of blood was collected into a plain Vacutainer, allowed to clot, and centrifuged, to obtain hemolysis-free serum that was kept frozen at $-80^{\circ} \mathrm{C}$ at the Epicentre Mbarara Research Centre, Mbarara, Uganda.

\section{Laboratory analysis}

We performed indirect monoclonal antibody-specific immobilization of platelet antigens (MAIPA) for 40 serum samples from thrombocytopenic HIV clients, to screen and identify antiplatelet antibodies. Antibody screening was done using platelets from a pool of six group $\mathrm{O}$ donors selected for their platelet genotype (Advanced Practical Diagnostics BVBA, Turnhout, Belgium); these were incubated with serum, and mouse monoclonal antibodies specific for platelet glycoproteins $\mathrm{Ia} / \mathrm{IIa}, \mathrm{Ib} / \mathrm{IX}$, IIb/IIIa, and anti $\beta$-2-microglobulin. Lysates were cleared by centrifugation and transferred to microplate wells precoated with goat anti-mouse immunoglobulin $\mathrm{G}$ ( $\mathrm{IgG}$ ). The bound complex was detected using goat peroxidase-coupled anti-human $\operatorname{IgG}$ and revealed by peroxidase substrate $O$-phenylenediamine. The reaction was stopped using sulfuric acid, and absorbance was read at $492 \mathrm{~nm}$. All positive antibody screens were identified, using a standard six-cell genotyped panel, by similar or additional methods. A participant was regarded to have antiplatelet antibodies if one or more platelet antiglycoproteins were identified.

\section{Statistical analysis}

Retrospective data from the ISS database and data from laboratory analyses were entered into a statistical software package of EXCEL ${ }^{\circledR} 5.0$ (Microsoft Corp, Redmond, WA, USA) and transferred to STATA 12 (StataCorp LP, College Station, TX, USA) to carry out data management and analysis, respectively. Descriptive statistics (median and interquartile range [IQR]) were used. Univariate and multivariate analyses using logistic regression were done to establish predictor variables. Proportions for categorical variables were compared using the chi-square test. The $P$-value was considered to be statistically significant when less than 0.05 .

\section{Ethical considerations}

We sought clients' informed consent, and the study was approved by the Institutional Review Committee of Mbarara University of Science and Technology, and the Uganda National Council for Science and Technology.

\section{Results}

Records for 15,030 HIV clients at enrollment into care at the Mbarara Regional Referral Hospital ISS clinic were used. The study group comprised 9,500 females. Participants had a median age of 35.0 (range 18-78; IQR 28-42) years.

Out of 15,030 participants, 2,617 had thrombocytopenia, giving an overall prevalence of $17.4 \%$ (95\% confidence interval [CI]: $16.8 \%-18.0 \%)$. The prevalence of thrombocytopenia among HIV clients who were ART-naïve $(n=2,675)$ was $17.8 \%$ (95\% CI: $17.1 \%-18.4 \%$ ), while that for clients who were on ART for up to 6 months $(n=6)$ was $13.0 \%(95 \%$ CI: $0.3 \%-21.9 \%$ ).

We used univariate and multivariate analyses to determine association of thrombocytopenia with clinical stage, CD4 count, ART, anemia, and leucopenia, which we found significant $(P<0.05)$ (Tables 1 and 2$)$.

Of the 40 thrombocytopenic samples tested for antiplatelet antibodies, two $(5.0 \%)$ had glycoprotein IIb/IIIa and $\mathrm{IIa} / \mathrm{Ia}$.

\section{Discussion}

In this study, the overall prevalence of HIV-related thrombocytopenia was $17.4 \%$ (95\% CI: $16.8 \%-18.0 \%$ ); this is comparable to the $20 \%$ reported in $\operatorname{Iran}^{12}$ and $12.7 \%$ in Ethiopia. ${ }^{13}$ 
Table I Correlation of thrombocytopenia with different participants' variables

\begin{tabular}{|c|c|c|c|c|}
\hline & \multicolumn{2}{|c|}{ Thrombocytopenia } & \multirow[t]{2}{*}{$P$-value } & \multirow[t]{2}{*}{$95 \% \mathrm{Cl}$} \\
\hline & $\begin{array}{l}\text { Absent, } \\
\mathrm{n}=(\%)\end{array}$ & $\begin{array}{l}\text { Present, } \\
n=(\%)\end{array}$ & & \\
\hline \multicolumn{5}{|c|}{ WHO clinical stage } \\
\hline Stage I & $3,627(35.2)$ & $584(27.0)$ & 0.000 & $14.8-17.6$ \\
\hline Stage 2 & $3,514(34.1)$ & 731 (33.7) & 0.000 & $1 \mid 4.8-145.4$ \\
\hline Stage 3 & I,728 (16.8) & $438(20.2)$ & 0.000 & $\mid 37.3-180.4$ \\
\hline Stage 4 & I,434 (I3.9) & $414(19.1)$ & 0.000 & I55.9-206.2 \\
\hline \multicolumn{5}{|c|}{$C D_{4}$ counts $(/ L)$} \\
\hline $0-199$ & $4,020(76.8)$ & $\mathrm{I}, 2 \mathrm{I} 4(23.2)$ & 0.000 & $28.0-32.2$ \\
\hline $200-499$ & $5,086(84.3)$ & $944(15.7)$ & 0.000 & $55.9-67.6$ \\
\hline Above 500 & 3,081 (89.2) & $374(10.8)$ & 0.000 & $35.5-45.6$ \\
\hline \multicolumn{5}{|l|}{ Anemia } \\
\hline No & $10,902(84.1)$ & $2,064(15.9)$ & 0.000 & $18 . \mid-19.8$ \\
\hline Yes & I,5I I (73.2) & $553(26.8)$ & 0.000 & $|73.5-2| 5.4$ \\
\hline \multicolumn{5}{|l|}{ Leucopenia } \\
\hline No & $12,329(82.8)$ & $2,554(17.2)$ & 0.000 & $|9.9-2| .6$ \\
\hline Yes & $84(57.1)$ & $63(42.9)$ & 0.000 & $260.4-503.3$ \\
\hline
\end{tabular}

Abbreviations: $\mathrm{CD}_{4}$, cluster of differentiation $4 ; \mathrm{Cl}$, confidence interval; $\mathrm{WHO}$, World Health Organization.

This is attributed to HIV-induced hemopoiesis dysfunction and platelet immunologic involvement, which aggravates their destruction. ${ }^{8}$ The prevalence of thrombocytopenia among HIV-infected, ART-naïve clients was $17.8 \%$ (95\% CI: $17.1 \%-18.4 \%$ ); this is similar to the $16.1 \%$ reported in Nigeria ${ }^{14}$ and $13.5 \%$ in Rwanda ${ }^{15}$ but higher than the $8.3 \%$ reported in Kampala, Uganda ${ }^{16}$ and the $5.9 \%$ reported in Ethiopia. ${ }^{17}$ The high prevalence of thrombocytopenia in this group is probably attributed to already established mechanisms of HIV-related thrombocytopenia. ${ }^{18,19}$ This study showed a positive effect of regimens containing the nucleoside analog reverse-transcriptase inhibitor, zidovudine (AZT), which is similar to other reports; ${ }^{17}$ thus exclusive use of prophylactic co-trimoxazole among the ART-naïve HIV clients may be an independent predictor of accelerated thrombocytopenia. Since we detected antiglycoproteins in one of the ART-naïve participants, it is likely that such antibodies cause thrombocytopenia. ${ }^{20}$

Table 2 Multivariate analysis of thrombocytopenia among participants

\begin{tabular}{lclll}
\hline Thrombocytopenia & $\begin{array}{l}\text { Odds } \\
\text { ratio }\end{array}$ & $\begin{array}{l}\text { Standard } \\
\text { error }\end{array}$ & P-value & $\mathbf{9 5 \%} \mathbf{C l}$ \\
\hline Age category & 1.058 & 0.025 & 0.017 & $1.010-1.108$ \\
WHO clinical stage & 1.049 & 0.026 & 0.001 & $1.084-1.377$ \\
$\mathrm{CD}_{4}$ counts & 0.690 & 0.248 & 0.000 & $0.643-0.740$ \\
Antiretroviral therapy & 0.658 & $0.08 \mathrm{I}$ & 0.001 & $0.518-0.837$ \\
Anemia & 1.484 & 0.099 & 0.000 & $1.303-1.691$ \\
Leucopenia & 2.797 & 0.545 & 0.000 & $1.909-4.099$ \\
\hline
\end{tabular}

Abbreviations: $\mathrm{CD}_{4}$, cluster of differentiation $4 ; \mathrm{Cl}$, confidence interval; $\mathrm{WHO}$, World Health Organization.
The prevalence of thrombocytopenia among HIV-infected clients who were on ART for up to 6 months was $13.0 \%$ (95\% CI: $0.3 \%-21.9 \%$ ); this is much higher than the $4.1 \%$ reported in Ethiopia. ${ }^{21}$ This is probably due to diminished use of AZT regimens, in our study population, due to associated anemia. ${ }^{22}$ We analyzed for ART combinations as a predictor of thrombocytopenia, and from this, we elucidate reduced thrombocytopenia in participants on AZT regimens. The observed prevalence may as well be attributed to factors linked to induced cytopenias that vary according to the participant's profile, the etiologic basis, and ART option. ${ }^{23}$ The occurrence of antiglycoprotein in one of the participants in this group shows antiplatelet antibody involvement in the etiology.

Using univariate and multivariate analyses to relate the independent predictors of thrombocytopenia, diminished CD4 counts, other cytopenias, and enrollment on ART showed significant association with the occurrence of thrombocytopenia in our study participants $(P<0.05)$, which is consistent with findings reported by other studies in the region. ${ }^{16,21}$ This may be due to defective hemopoiesis and the effect of ART, as previously reported. ${ }^{21,24}$ The study found a significant association of thrombocytopenia with other cytopenias in all HIV stages (refer to Table 3 ). This may be due to defective bone marrow, accelerated platelet destruction, and to AZT- or stavudine-containing regimens. ${ }^{25}$

There was an increasing risk of thrombocytopenia with HIV infection progression, and this is similar to findings from other studies..$^{17,26}$ This may be because thrombocytopenia is greater in advanced HIV infection. ${ }^{15}$

The antiplatelet antibody prevalence of $5.0 \%$ is comparable with the $9.4 \%$ found among HIV Chilean population ${ }^{27}$ but lower than the $17.0 \%$ in the Italian population. ${ }^{28}$ The higher anti-human platelet antigens (HPAs) against IIb/IIIa than $\mathrm{Ia} / \mathrm{IIa}$ is due to their close association with the chronic

Table 3 Association of cytopenias and clinical stages of HIV infection at enrollment

\begin{tabular}{llllll}
\hline Cytopenia & \multicolumn{4}{l}{ WHO HIVIAIDS clinical stage } & P-value \\
\cline { 2 - 5 }$(\mathbf{n}, \%)$ & $\mathbf{I}$ & $\mathbf{2}$ & $\mathbf{3}$ & $\mathbf{4}$ & \\
\hline Thrombocytopenia & 584 & 731 & 438 & 414 & 0.000 \\
$(\mathrm{n}=2,167)$ & $(13.9)$ & $(17.2)$ & $(20.2)$ & $(22.4)$ & \\
Anemia & 230 & 430 & 567 & 486 & 0.000 \\
$(\mathrm{n}=|, 7| 3)$ & $(5.5)$ & $(10.3)$ & $(26.2)$ & $(26.3)$ & \\
Leucopenia & 15 & 27 & 44 & 35 & 0.000 \\
(n=I2I) & $(0.36)$ & $(0.64)$ & $(2.0)$ & $(1.9)$ & \\
Pancytopenia & $3 \mid$ & 23 & 16 & 38 & 0.000 \\
(n=I08) & $(29.0)$ & $(21.5)$ & $(15.0)$ & $(35.5)$ & \\
\hline
\end{tabular}

Abbreviations: AIDS, acquired immune deficiency syndrome; HIV, human immunodeficiency virus; WHO, World Health Organization. 
thrombocytopenic states associated with HIV. ${ }^{29}$ Anti-HPA-5, which targets Ib/IX, was missing in our study participants, as these are linked to thrombocytopenia due to neonatal alloimmunization. ${ }^{30}$ Antiplatelet antibodies were seen in mild and moderate thrombocytopenic clients, which implies that severe thrombocytopenia is not associated with the production of antiplatelet antibodies, as already reported. ${ }^{28}$

\section{Limitation of the study}

The key limitation of study was the small sample size of participants enrolled for antiplatelet antibody assay owing to time and financial constraints.

\section{Recommendations}

The authors recommend a larger study to be carried out and that as a basis of critical care and management, immune thrombocytopenia should be considered in our study population.

\section{Conclusion}

This study has observed a high prevalence of thrombocytopenia, especially in the ART-naïve population, and the occurrence of antiglycoproteins in our sample population. These results indicate that there is a need to monitor platelet counts and to initiate platelet component transfusion among HIV thrombocytopenic clients, in our current blood banking practice.

\section{Acknowledgments}

The authors wish to thank the study participants and the ISS Clinic team. We are grateful to the Epicentre Mbarara Research Centre, the Medical Education Partnership Initiative - Medical Education Services for All Ugandans (MEPI-MESAU) consortium, and the Uganda Research Student Support Fund (URSSF) for their support. We are grateful to Dr Mark Siedner and Michael Kanyesigye for their contributions to this study. This work was made possible by Medical Education for Equitable Services to All Ugandans a Medical Education Partnership Initiative (5R24TW008886) from the Office of Global AIDS Coordinator and the U. S. Department of Health and Human Services, Health Resources and Services Administration and National Institutes of Health.

\section{Author contributions}

IMT participated in study conception and design; data acquisition, analysis, and interpretation; and manuscript drafting and revision. WRM participated in study conception; data acquisition, analysis, and interpretation; and manuscript drafting. EM participated in study conception and design; data acquisition, analysis, and interpretation; and manuscript drafting. YB participated in study conception and design; data acquisition, analysis, and interpretation; and critically revised the manuscript. BN participated in study conception and design; data acquisition, analysis and interpretation; and critically revised the manuscript.

\section{Disclosure}

The authors report no conflicts of interest in this work.

\section{References}

1. Cosby CD. Hematological disorders associated with human immunodeficiency virus and AIDS. $J$ Infus Nurs. 2007;30(1):22-32.

2. Giles. C. The platelet count and mean platelet volume. Br J Haematol. 1981;48(1):31-37.

3. Dacie JV, Lewis SM. Practical Haematology. 7th ed. Edinburgh: Elsevier Churchill Livingstone; 1991.

4. Sloand EM, Klein HG, Banks SM, Vareldzis B, Merritt S, Pierce P. Epidemiology of thrombocytopenia in HIV infection. Eur J Haematol. 1992;48(3):168-172.

5. Liebman H. Other immune thrombocytopenias. Semin Hematol. 2007;44(4 Suppl 5):S24-S34.

6. Ballem PJ. Belzberg A, Devine DV, et al. Kinetic studies of the mechanism of thrombocytopenia in patients with human immunodeficiency virus infection. N Eng J Med. 1992;327(25):1779-1784.

7. McDonald EJ. and Butler A. Immune thrombocytopaenia in adults: a single-centre retrospective review of patients presenting over 7 years. NZ Med J. 2010;123(1312):18-25.

8. Coyle TE. Hematologic complications of human immunodeficiency virus infection and the acquired immunodeficiency syndrome. Med Clin North Am. 1997;81(2):449-470.

9. Johannessen A, Naman E, Ngowi BJ, et al. Predictors of mortality in HIV-infected patients starting antiretroviral therapy in a rural hospital in Tanzania. BMC Infect Dis. 2008;8:52.

10. Racoosin JA, Kessler CM. Bleeding episodes in HIV-positive patients taking HIV protease inhibitors: a case series. Haemophilia. 1999;5(4): 266-269.

11. Natukunda B. Post-Transfusion and Maternal Red Blood Cell Alloimmunization in Uganda [doctoral thesis]. Leiden: Leiden University; 2013.

12. Alaei K, Alaei A, Mansoori D. Thrombocytopenia in HIV-infected patients, Islamic Republic of Iran. East Mediterr Health J. 2000;8(6): 758-764.

13. Addis Z, Yitayew G, Tachebele B. Prevalence of some hematological abnormalities among HIV positive patients on their first visit to a tertiary health institution in Ethiopia; A cross sectional study. International Blood Research and Reviews. 2014;2(6):270-278.

14. Akinbami A, Olajumoke O, Titilope A, et al. Hematologic abnormalities in treatment-naive HIV patients. Infect Dis (Auckl). 2010;3:45-49.

15. Munyazesa E, Emile I, Mutimura E, et al. Assessment of haematological parameters in HIV-infected and uninfected Rwandan women: a crosssectional study. BMJ Open. 2012;2(6):e001600.

16. Kyeyune R, Saathoff E, Ezeamama AE, Löscher T, Fawzi W, Guwatudde D. Prevalence and correlates of cytopenias in HIV-infected adults initiating highly active antiretroviral therapy in Uganda. $B M C$ Infect Dis. 2014;14:496.

17. Wondimeneh Y, Muluye D, Ferede G. Prevalence and associated factors of thrombocytopenia among HAART-naive HIV-positive patients at Gondar University Hospital, Northwest Ethiopia. BMC Res Notes. 2014;7:5. 
18. Li Z, Nardi MA, Karpatkin S. Role of molecular mimicry to HIV-1 peptides in HIV-1-related immunologic thrombocytopenia. Blood. 2005;106(2):572-576.

19. Moses A Nelson J, Bagby GC Jr. The influence of human immunodeficiency virus-1 on hematopoiesis. Blood. 1998;91(5):1479-1495.

20. Cines DB, Liebman H, Stasi R. Pathobiology of secondary immune thrombocytopenia. Semin Hematol. 2009;46(1 Suppl 2):S2-S14.

21. Enawgaw B, Alem M, Addis Z, Melku M. Determination of hematological and immunological parameters among HIV positive patients taking highly active antiretroviral treatment and treatment naive in the antiretroviral therapy clinic of Gondar University Hospital, Gondar, Northwest Ethiopia: a comparative cross-sectional study. BMC Hematol. 2014; $14: 8$

22. Montaner JS, Le T, Fanning M, et al. The effect of zidovudine on platelet count in HIV-infected individuals. J Acquir Immune Defic Syndr. 1990;3(6):565-570.

23. Sullivan PS, Hanson DL, Chu SY, Jones JL, Ward JW. Epidemiology of anemia in human immunodeficiency virus (HIV)-infected persons: results From the Multistate Adult and Adolescent Spectrum of HIV Disease Surveillance Project. Blood. 1998;91(1):301-308.

24. Berhane K, Karim R, Cohen MH, et al. Impact of highly active antiretroviral therapy on anemia and relationship between anemia and survival in a large cohort of HIV-infected women: Women's Interagency HIV Study. J Acquir Immune Defic Syndr. 2004;37(2):1245-1252.
25. Moore RD, Keruly JC, Chaisson RE. Anemia and survival in HIV infection. J Acquir Immune Defic Syndr Hum Retrovirol. 1998;19(1): 29-33.

26. Ferede G, Wondimeneh Y. Prevalence and related factors of anemia in HAART-naive HIV positive patients at Gondar University Hospital, Northwest Ethiopia. BMC Hematol. 2013;13:8.

27. Palomo I, Alarcón M, Sepulveda C, Pereira J, Espinola R, Pierangeli S. Prevalence of antiphospholipid and antiplatelet antibodies in human immunodeficiency virus (HIV)-infected Chilean patients. J Clin Lab Anal. 2003;17(6):209-215.

28. Riccio A, Natale D, Fratellanza G, et al. The lack of correlation between the positivity of anti-platelet antibodies and the presence of thrombocytopenia in course of HIV infection. Boll Soc Ital Biol Sper. 1993;69(3): 203-208.

29. Aster RH, Newman PJ. HPA-1a/b(P1A1/A2, Zwa/b): the odyssey of an alloantigen system. Immunohematology. 2007;23(1):2-8.

30. Kaplan C, Morel-Kopp MC, Kroll H, et al. HPA-5b (Br(a)) neonatal alloimmune thrombocytopenia: clinical and immunological analysis of 39 cases. Br J Haematol. 1991;78(3):425-429.
Journal of Blood Medicine

\section{Publish your work in this journal}

The Journal of Blood Medicine is an international, peer-reviewed, open access, online journal publishing laboratory, experimental and clinical aspects of all topics pertaining to blood based medicine including but not limited to: Transfusion Medicine; Blood collection, Donor issues, Transmittable diseases, and Blood banking logistics; Immunohematology; Artificial and alternative

\section{Dovepress}

blood based therapeutics; Hematology; Biotechnology/nanotechnology of blood related medicine; Legal aspects of blood medicine; Historical perspectives. The manuscript management system is completely online and includes a very quick and fair peer-review system. Visit http://www.dovepress.com/ testimonials.php to read real quotes from published authors. 